\title{
Characterization of Doum Palm Seed Kernel as Natural Sorbent for Metal Ions Removal from Gombe Ternary Wastewater
}

\author{
Idris Misau Muhammad ${ }^{1}$, Abdulwadud Yusuf Abdulkarim ${ }^{1}$, Sagir Adamu ${ }^{2}$ \\ ${ }^{1}$ Abubakar Tafawa Balewa University \\ Dass road, P. M. B. 0248, Bauchi, 740272, Nigeria \\ ${ }^{2}$ Ahmadu Bello University \\ Zaria, 810211, Nigeria
}

DOI: $10.22178 /$ pos.48-2

LCC Subject Category: QD1-65

Received 28.06.2019

Accepted 25.07.2019

Published online 31.07.2019

Abstract. Water pollution is one of the major challenges in cities and industrialized areas of the world. The effluent from Gombe ternary wastewater pollutes the surrounding waters thereby constituting health threat to the populace within its vicinity. In view of the above, a bio-sorption study of zinc and lead ions from Gombe ternary wastewater using doum palm seed kernel was carried out. The wastewater was characterized and was found to contain 0.03 $\mathrm{mg} / \mathrm{l}$ lead metal ion and $0.81 \mathrm{mg} / \mathrm{l}$ zinc ion. The doum palm kernel bio-sorbent was obtained after oil extraction from the seed and processed as contained in the method mentioned in this paper. The kernel residue was characterized for functional groups using FTIR, surface morphology using SEM, surface area using $\mathrm{BET}$, and elemental composition using XRF. The results indicated that the doum palm kernel is harmless, and possesses functional groups on its surface, which may be substituted with the metallic ions present in the wastewater. This gives the kernel the ability to adsorb positively charged ions on its surface by simple chemisorption. This mechanism is supported by the rough surface observed in the scanning electron microscopy. Adsorption and desorption of nitrogen was made at STP and the curve indicated very high correlation of close to unity. The surface area measured by multi BET method was recorded as $13.464 \mathrm{~m}^{2} / \mathrm{g}$. This value is not high enough to adsorb metals by physical adsorption.

(c) 2019 The Authors. This article is licensed under a Creative Commons Attribution 4.0 License (c) (1)

Keywords: Doum palm; kernel; characterization; zinc; lead; chemisorption.

\section{INTRODUCTION}

The pollution of water resources due to the disposal of heavy metals has been causing worldwide concern. The main sources of these metals are mining, metallurgical, chemical manufacturing, tannery, battery manufacturing industries, fossil fuel, the modern chemical industry is based largely on catalysts, many of which are metals or metal compounds, production of plastics, such as polyvinyl chloride, involves the use of metal compounds, particularly as heat stabilizers, etc. The effects of heavy metals such as copper, zinc, mercury, chromium and cadmium on human health have been investigated extensively. Zinc is one of these heavy metals which is considered as toxic materials if it exceeds the acceptable level. Its oxide is widely used as a white pigment in paints, and as a catalyst in the manufacture of rubber. Zinc waste causes environmental and public health problems. Although humans can handle proportionately large concentrations of zinc, excess zinc can be harmful. The free zinc ion in solution is highly toxic to plants, invertebrates, and even vertebrate fish. Excess amount of zinc may cause zinc toxicity which leads to a severe hemolytic anomie, liver and kidney damages; vomiting and diarrhea are possible symptoms [23]. The consumption of fruit juices stored in galvanized cans has resulted in mass parrot poisonings with zinc [4].

Leather manufacture is a water-intensive process and generates a significant volume of liquid and solid waste. Only about $50 \%$ of the raw hide collagen ends up as finished leather whereas only about $20 \%$ of the large number of chemicals used in the process is absorbed by leather [7]. Typically, one ton of wet salted hide generates about half a ton of solid wastes (of different dry matter content) and almost as much of sludge dewatered to about $30 \%$ of dry matter content. Untreated liquid, solid and air emissions generated by the tanning industry can thus pose a se- 
rious threat to the environment, particularly to surface and ground water. Lower production costs because of lower wage levels and less stringent environmental protection laws are considered the primary factors responsible for relocation of the tanning industry to the South during the last 2-3 decades [6].

Water is a very vital substance to all natural and anthropogenic activities. It regenerates and shape, oceans, seas, rivers, lakes and forests, becoming part of the identity of environments and landscapes and of paramount importance for the development of ecosystems and human life [11]. Water is a vital resource needed for the sustenance of life including aquaculture. Living organisms requires water for existence, growth and proliferation. Furthermore, water is also essential for socioeconomic development and maintenance of the ecosystem. As such, water is an important component of all living things. Interestingly, nearly $70 \%$ of the earth is occupied by water including fresh, brackish and marine [13]. Basically, water exist in the form of solid (ice), fluids (vapor and liquid). Besides the usefulness of water to living organisms, it has found applications in several areas including industries, agriculture, transportation, energy and domestic uses. Water is a natural resource of fundamental importance. It supports all forms of life and creates jobs and wealth in the water sector, tourism, recreation and fisheries. Without water life as it exists on our planet is impossible. $97.5 \%$ of water on the earth is salt water, leaving only $2.5 \%$ as fresh water of which over two thirds is frozen in glaciers and polar ice caps. The remaining unfrozen fresh water is mainly found as groundwater, with only a small fraction present above the ground or in the air. Freshwater is a renewable resource, yet the world's supply of clean, fresh water is steadily decreasing. Water demand already exceeds supply in many parts of the world, and as world population continues to rise at an unprecedented rate, many more areas are expected to experience this imbalance in the near future $[1,25]$.

Water pollution is a major problem for the environment and can negatively affect the sustainability of water resources. Coagulationflocculation is an important unit operation for the primary treatment of wastewater whereas activated carbon is a secondary treatment for wastewater. Coagulation removes dissolved and colloidal substances in wastewater by overcoming the interparticle repulsive energy barrier by simply increasing the ionic strength and destabilizes colloids by neutralizing the forces that keep them apart. Flocculation occurs through the bridging between particles to form larger flocs for sedimentation to take place natural coagulants have been proven to be effective in treating wastewater. Today, the prime concern of the environmental engineers is how to lower the coagulants and flocculants cost and to improve the characteristics of the produced sludge for safe utilizing. Aloe Vera can be promoted as a good natural flocculant in surface water for the removal of turbidity [17].

Zinc is one of the trace elements that occur in organisms, mainly in the liver, kidneys and in the bones. The metabolism of zinc and of other elements is subject to hormonal regulation with participation of glycol-corticoids, insulin and catecholamine. Also, zinc transformations are aided by interleukin-1, related with the immune system, inflammatory conditions and stress [18]. Its most important function is participation maintaining the activity of numerous enzymes which determine the proper course of physiological processes. The human body contains approximately $2.3 \mathrm{~g}$ zinc, and it has a dietary value as a trace element. Its functions involve mainly enzymatic processes and DNA replication. The human hormone insulin contains zinc, and it plays an important role in sexual development. Minimum daily intake is $2-3 \mathrm{~g}$, this prevents deficiencies. The human body only absorbs $20-40 \%$ of zinc present in food, consequently many people drink mineral water rich in zinc. Symptoms of zinc deficiencies are tastelessness and loss of appetite. Children's immune systems and enzyme systems may be affected. Higher zinc application appears to protect people from cadmium poisoning. Zinc may also decrease lead absorption. The relation copper/zinc in the human body is an important characteristic. One may also absorb zinc overdoses. This does not occur very regularly. Symptoms include nausea, vomiting, dizziness, colic, fevers and diarrhea and mostly occur after intake of 4-8 $g$ of zinc. Intake of $2 \mathrm{~g}$ of zinc sulphate at once cause acute toxicity leading to stomach aches and vomiting. Strikingly, zinc belongs to the same elemental group in the periodic chart as cadmium and mercury, which are both toxic. Examples of zinc-related health effects also include mucous membrane infection from zinc chloride (lethal dose 3-5 g), and zinc vitriol poisoning (lethal dose $5 \mathrm{~g}$ ). Lead is very poisonous. It can damage kidneys, male reproductive sys- 
tem, liver, lungs, spleen, bone marrow, and bone. It may cause anemia, and possibly affect the memory [12]. The effects of lead on adults are generally reversible, but not for children under six years of age. Lead intake can affect a child's mental and physical growth, and learning ability. A particular concern is water used for formula fed infants as it can contribute $40-60 \%$ of an infant's lead intake [12].

Many physicochemical methods for heavy metal removal from aqueous solution have been developed. These methods include precipitation, resin chelation, electrochemical deposition, reverse osmosis, ion exchange, coagulation and solidphase extraction [19]. These techniques however, have disadvantages such as incomplete metal removal, high reagent and energy requirements and generation of toxic sludge.

The environmental pollution is becoming the most challenging threat to the human beings as a result of rapid industrialization and growth population throughout the world. Mostly the areas situated around industrial belts are under stress due to the continuous disposal of the untreated wastes from the various industries. The quality of water is continuously deteriorating due to addition of toxic as well as colored effluents from various industries [15]. There are many types of wastewaters that pollute the environment especially the aquatic ecosystem. Textile wastewater, industry used water, landfill leachate, ternary wastewater, and oily wastewater are the examples that causes pollution to the environment [14]. Ternary wastewater also contains high BOD and COD value, suspended solids and toxic compounds. Colored wastewaters or ternary wastewaters also introduce the potential danger to human being through the process of bioaccumulation [14]. Wastewater discharge from chemical industries contain high amount of heavy metals such as $\mathrm{Cr}, \mathrm{Cu}, \mathrm{Cd}, \mathrm{Ni}, \mathrm{As}, \mathrm{Pb}, \mathrm{Hg}$, and $\mathrm{Zn}$ which are hazardous to the environment [14]. The introduction of chemicals into the environment by human activities can represent a serious risk to environmental and human health. The Chemical Abstract Service database at present includes more than 33 million organic and inorganic substances and over 59 million sequences. This database is updated daily and, on average, approximately 4000 new substances are added each day [16]. Therefore, it is important to remove heavy metals from the waste stream. The removal of heavy metals from industrial effluents is a field of research that has attracted increasing attention from the scientific community as the quest for green chemistry takes center stage. Heavy metals in wastewaters are hazardous to the environment and therefore their removal before waste water discharge is apparent [19]. These substances are stable and persistent environmental contaminants since they are nonbiodegradable [19]. Chromium is one of the toxic metals often found in effluents discharged from industries involved in paints, pigments, dyes, textiles, leather tanning, electroplating, metal finishing, nuclear power plants and chromate preparation. Chromium can exist in several oxidation numbers but only chromium (III) and chromium (VI) are stable enough to occur in the environment. The hexavalent form is more toxic than the trivalent one.

The continuous discharge of contaminated water into a body of water and soil prevents their capability for self-purification. Thus, the organic and inorganic compounds in wastewater must be eliminated by specific treatments [22]. The process type and sequence depend on the origin of wastewater and the destination and/or the use it will have. The wastewater characterization is also essential for an adequate design of efficient treatment technologies. The treatment of industrial wastewaters is more complex than sewage wastewater, and therefore often requires tertiary/advanced treatment. Heavy metals released to environment have continuously increasing trends as a result of industrial activities and technological developments, which is a significant threat to the environment and public health due to their toxicity, accumulation in food chain and persistence in nature. Toxic heavy metal ions introduced to the aquatic streams by means of various industrial activities viz. mining, refining ores, fertilizer industries, tanneries, batteries, paper industries, pesticides, etc. [5]. Several episodes due to heavy metal contamination in aquatic environment have increased the awareness about the heavy metal toxicity. Moreover, high intakes of these metals can cause liver, kidney and pancreas damage [5].

Contamination of aquatic environments by acidic drainage and associated toxic metals is a widespread problem in watersheds affected by hardrock mining. Adverse effects of acidity and associated toxic metals on aquatic ecosystems may extend far downstream from sources of acidic drainage [6]. Water quality and the risk to waterborne diseases are critical public health concern in many developing countries. It observed 
that close to a billion people most living in the developing world do not have access to safe and adequate water. Most water sources in developing countries are polluted by both organic and chemical pollutants which include heavy elements [8].

Heavy metal contamination of aquatic ecosystem has long been recognized as a serious problem, it may have lethal effect on ecological balance of recipient environment and diversity of aquatic organism. Water is a finite resource that is very essential for human existence, agriculture and industry. Without doubt, inadequate quantity and quality of water supply have serious impact on water resources management and environmental sustainability [9]. National Pollutant Discharge Elimination System (NPDES) permit development at the Savannah River Site (SRS), limits for $\mathrm{Zn}$ were proposed based on a simplified "recalculation" method. The recalculation was performed in 2007 resulting in a proposed limit for $\mathrm{Zn}$ of $153.2 \mu \mathrm{g} / \mathrm{l}$ [10].

Rapid industrialization and development released excessively heavy metals into the environment. Industries such as mining, metal plating and battery manufacturing, result in the release of heavy metals to aquatic ecosystem. Hence, it is important to remove heavy metal from the waste stream [20].

Toxicity of stream water was associated with elevated concentrations of several dissolved metals, especially zinc and copper. Laboratory tests demonstrated that dissolved zinc was highly toxic to amphipods, less toxic to fathead minnows, and least toxic to brook trout, Salvelinus fontinalis, and the predominant fish species in the Animas River watershed study area. Significant toxic effects of zinc on early life stages of brook trout occurred at concentrations of $960 \mu \mathrm{g} / \mathrm{l}$ or greater [6].

Interestingly, the present study tries to address the polluting effect of Gombe ternary wastewater using doum palm seed kernel which is also a waste contributing nothing to the environment when thrown other than litter.

\section{METHODOLOGY}

Ternary wastewater was obtained from Gombe and fully analyzed physically and chemically. The analysis on the effluent water from the ternary for the presence of heavy metals was made using atomic adsorption spectrophotometer (AAS). All other water parameters were measured using DR2000 spectrophotometer. Sorption study was conducted using 6-cell jar test kit under batch study. Doum palm seed was obtained and processed from Gombe. FTIR Spectroscopy was used to determine the frequency changes in the functional groups in the doum palm sample. The spectra were collected using Shimazu FTIR8400 S equipped with diffuse reflectance accessory within the range of $400-4000 \mathrm{~cm}^{-1}$. The samples were ground in an agate pestle and mortar. A small amount of sample was transferred to diffuse reflectance rods in the form of thin film. The samples were dried for $6 \mathrm{~h}$ in a heating oven. With regard to recording the spectra, 16 scans and $8 \mathrm{~cm}^{-1}$ resolutions were applied in accordance with [1]. The background obtained from a scan of empty rod was automatically subtracted from the sample spectra. All spectra were plotted using the same scale on the absorbance axis. The surface area and pore analysis was made using VSorb 2800P surface area and Porosimetry Analyzer. This was made at ambient temperature and the sample was degassed at $100{ }^{\circ} \mathrm{C}$ using nitrogen. Surface morphology of the material was determined using scanning electron microscope (SEM) at $15 \mathrm{kV}$-mapping and 5000 magnifications.

\section{RESULTS AND DISCUSSION}

Table 1 presents the result obtained for the analysis of Gombe ternary effluent. The concentrations of zinc and lead in the wastewater effluent are 0.81 and 0.03 milligram per liter respectively. This may be harmful to aquatic life, and may have a long term accumulative effect on humans.

Table 1 - Values of heavy metals detected in Gombe Ternary effluent using AAS

\begin{tabular}{|l|l|c|}
\hline No & Metal detected & Concentration $(\mathrm{mg} / \mathrm{l})$ \\
\hline 1. & Lead & 0.03 \\
\hline 2. & Zinc & 0.81 \\
\hline 3. & Copper & 1.10 \\
\hline 4. & Iron & 0.50 \\
\hline 5. & Manganese & 0.40 \\
\hline 6. & Calcium & 28.1 \\
\hline 7. & Potassium & 26.0 \\
\hline 8. & Magnesium & 19.7 \\
\hline
\end{tabular}


Different measured quantities of the processed doum palm seed kernel (DPSK) powder was charged into each of the 6-cell jar test apparatus and stirred for 30 minutes. The following results were obtained as presented in Table 2 .

Table 2 - Result of batch sorption study on Gombe Ternary effluent using (dpsk) at 30 minutes' contact under variable dosage

\begin{tabular}{|c|c|c|}
\hline \multirow{2}{*}{ Dosage (ppm) } & \multicolumn{2}{|c|}{ Metal concentration (mg/l) } \\
\cline { 2 - 3 } & Zinc & Lead \\
\hline 0 & 0.81 & 0.03 \\
\hline 167 & 0.07 & 0 \\
\hline 334 & 0.06 & 0 \\
\hline 500 & 0.03 & 0 \\
\hline 668 & 0.01 & 0 \\
\hline 835 & 0 & 0 \\
\hline
\end{tabular}

Table 3 presents the result obtained when time was varied at constant speed and optimum dosage.

Table 3 - Effect of time on zinc removal from Gombe Ternary wastewater at room temperature

\begin{tabular}{|c|c|c|}
\hline $\begin{array}{c}\text { Zinc conc. } \\
(\mathrm{mg} / \mathrm{l})\end{array}$ & $\begin{array}{c}\text { Time } \\
(\mathrm{min} .)\end{array}$ & $\begin{array}{c}\text { Zinc removal } \\
(\%)\end{array}$ \\
\hline 0.81 & 0 & 0 \\
\hline 0.5 & 32 & 38 \\
\hline 0.24 & 40 & 70 \\
\hline 0.08 & 48 & 90 \\
\hline
\end{tabular}

Table 4 presents the effect of temperature on zinc removal from Gombe Ternary wastewater.

Table 4 - Effect of temperature on zinc removal from Gombe Ternary wastewater

\begin{tabular}{|c|c|c|c|}
\hline $\begin{array}{c}\text { Temperature } \\
\left({ }^{\circ} \mathrm{C}\right)\end{array}$ & $\begin{array}{c}\text { Zinc } \\
\text { conc. } \\
(\mathrm{mg} / \mathrm{l})\end{array}$ & $\begin{array}{c}\text { Zinc } \\
\text { uptake } \\
(\mathrm{mg} / \mathrm{l})\end{array}$ & $\begin{array}{c}\text { Zinc } \\
\text { removal } \\
(\%)\end{array}$ \\
\hline 25 & 0.81 & 0 & 0 \\
\hline 30 & 0.65 & 0.16 & 20 \\
\hline 40 & 0.2 & 0.61 & 75 \\
\hline 45 & 0.08 & 0.73 & 90 \\
\hline 50 & 0 & 0.81 & 100 \\
\hline
\end{tabular}

Figure 1 presents the FT-IR spectrum of doum palm kernel.

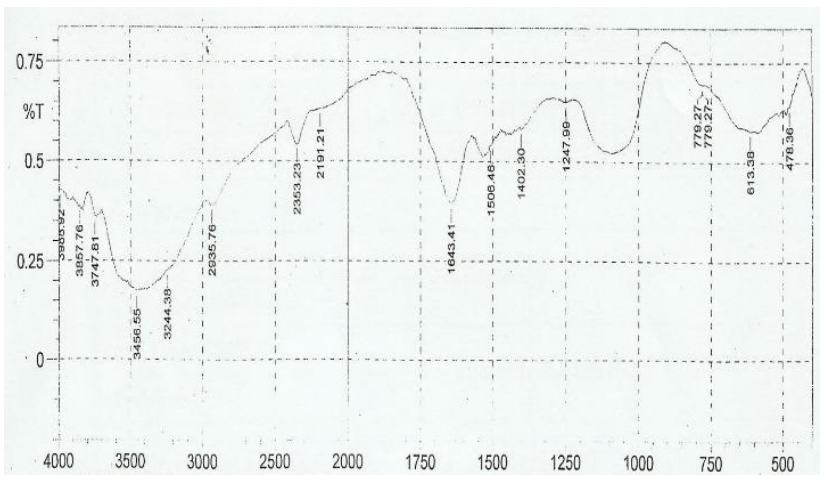

Figure 1 - FT-IR spectrum of Doum Palm Seed kernel

The FTIR Spectroscopy is an important analytical technique which detects the vibration characteristics of chemical functional groups in a molecule. On interaction of an infrared light with the matter, chemical bonds will stretch, contract and bend. As a result, chemical functional group tends to absorb infrared radiation in a specific wavelength range regardless of the structure of the rest of the molecule. Based on these principles, effect of pre-treatment on the surface functional groups of doum palm kernel was adequately studied in the range of $400-4000 \mathrm{~cm}^{-1}$ as shown in Figure 1.

FTIR analysis for doum palm kernel was taken before any uptake of pollutant. The main functional groups present on surface of doum palm kernel were amino, carboxylic, phosphate and carbonyl. The spectra of the kernel showed peaks at $3747.81,3456.55 \mathrm{~cm}^{-1}$ which resulted from presence of hydroxyl group and $\mathrm{NH}$ stretching respectively, while peak at $3244.38 \mathrm{~cm}^{-1}$ resulted from presence of ammonium ion on the surface. Peak at $2191.21 \mathrm{~cm}^{-1}$ resulted from the presence of medial alkyne $\mathrm{C} \equiv \mathrm{C}$ (acetylenic compounds). The spectra showed the presence of olefenic alkene group in the structure of the kernel as it depicts a peak at $1643.41 \mathrm{~cm}^{-1}$. Aromatic ring stretching of $\mathrm{C}=\mathrm{C}-\mathrm{C}$ group resulted when the spectra showed a peak at $1506.46 \mathrm{~cm}^{-1}$. The peak at $1402.30 \mathrm{~cm}^{-1}$ indicates the presence of phenol or tertiary alcohol $\mathrm{OH}$ bend. The $\mathrm{C}-\mathrm{C}$ bond stretch resulting from aryl skeletal vibration has a peak at $1247.99 \mathrm{~cm}^{-1}$. An indication of the presence of aliphatic chloro compounds showed a peak at $779.27 \mathrm{~cm}^{-1}$. Alkyne $\mathrm{C}-\mathrm{H}$ bend has peak at 613.38 $\mathrm{cm}^{-1}$ while alcohol $\mathrm{OH}$ out of plane depicts its peak at $478.36 \mathrm{~cm}^{-1}$. The presence of $\mathrm{OH}$ - ion on the surface will have a good chemisorption ability between the surface and the $\mathrm{Zn}^{2+}$ from the ternary wastewater. 
Adsorption and desorption of nitrogen at standard temperature and pressure (STP) was performed using and data plotted using linear isotherms as presented in Figure 2.

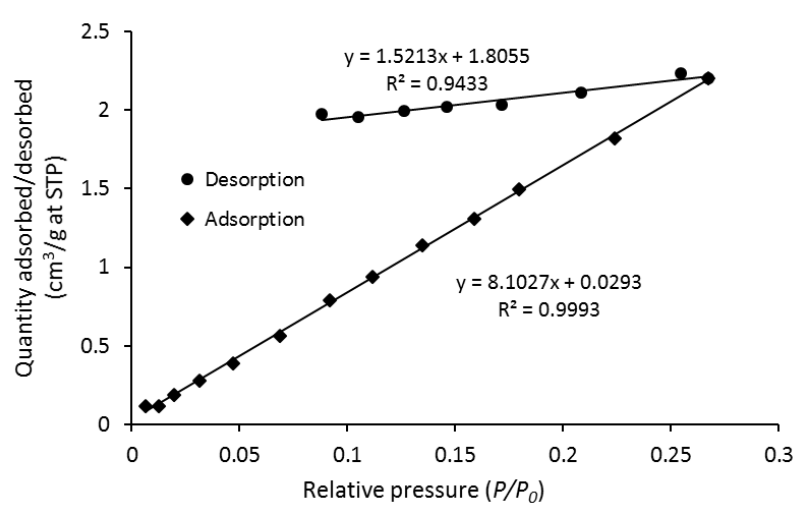

Figure 2 - Linear isotherm plot for nitrogen adsorption/desorption at STP on Doun Palm kernel

The volume adsorbed and desorbed correlated very well with both R2 close to 1 . The surface area was measured using multi BET method. The surface area by this method was found to be $13.46 \mathrm{~m}^{2} / \mathrm{g}$ while the surface area by Langmuir technique $31.25 \mathrm{~m}^{2} / \mathrm{g}$.

Scanning electron microscopy (SEM) analysis was performed to study the morphology of the adsorbent material. The samples were mounted on brass stubs using double-sided adhesive tape. SEM photographs were taken with a scanning electron microscope at various magnifications. The working distance of $12.5 \mathrm{~mm}$ was maintained, and the images were collected at an acceleration voltage of $5 \mathrm{kV}$ while using a secondary electron detector. The scanning Electron Microgram which depicts the surface morphology of doum palm kernel was made as shown in Figure 3.

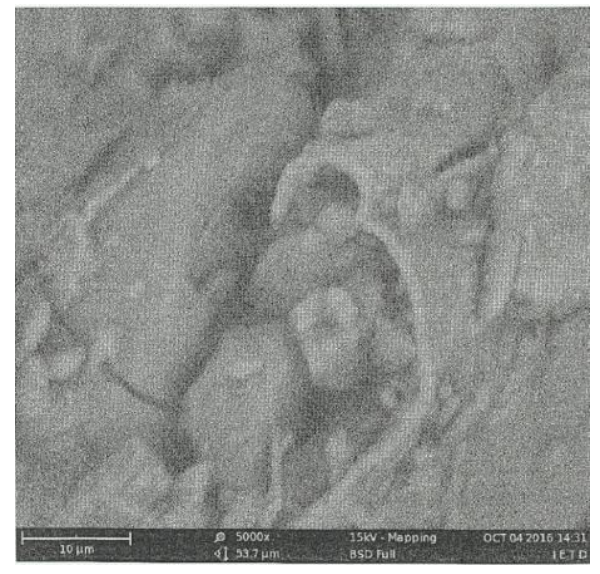

Figure 3 - Scanning Electron Microgram of doum palm kernel
SEM microgram showed asymmetric pores that were rough and cylinders on the surface of the doum palm kernel before ion adsorption. These cylinders seem to be composed of multicellular tubes bound together by lignin. The rough surface of the doum palm kernel can improve the interaction with metal ions. This conform very well with [3] and [21] who studied the adsorption of $\mathrm{Cu}^{2+}$ on date palm trunk fiber.

In X-ray fluorescence (XRF) spectrometry, the characteristic spectral line radiation emitted by the analyte is measured to determine the concentration of elements in a given sample [24]. From the spectroscopy results, doum palm kernel was found to contain oxides of the following metals as presented in Table 4.

Table 4 - Elemental Composition of Doum Palm Kernel as Measured by Xrf

\begin{tabular}{|l|l|c|}
\hline \multicolumn{1}{|c|}{ No } & \multicolumn{1}{|c|}{ Elements } & Composition (\%) \\
\hline 1. & $\mathrm{P}$ & 7.3 \\
\hline 2. & $\mathrm{~S}$ & 3.6 \\
\hline 3. & $\mathrm{~K}$ & 43.4 \\
\hline 4. & $\mathrm{Ca}$ & 13.2 \\
\hline 5. & $\mathrm{Ti}$ & 0.2 \\
\hline 6. & $\mathrm{Mn}$ & 1.5 \\
\hline 7. & $\mathrm{Fe}$ & 2.0 \\
\hline 8. & $\mathrm{Ni}$ & 0.4 \\
\hline 9. & $\mathrm{Cu}$ & 0.9 \\
\hline 10. & $\mathrm{Se}$ & 4.0 \\
\hline 11. & $\mathrm{Mo}$ & 2.0 \\
\hline 12. & $\mathrm{Ag}$ & 18.0 \\
\hline 13. & $\mathrm{Ba}$ & 0.4 \\
\hline 14. & $\mathrm{Re}$ & 3.1 \\
\hline & \multicolumn{2}{c|}{ Total } \\
\hline
\end{tabular}

\section{CONCLUSION}

Doum palm seed kernel was successfully processed and characterized using FTIR for functional groups present, SEM for surface morphology, multi BET for surface area, and XRF for elemental composition. Sorption of lead and zinc ions were made simultaneously using batch adsorption technique on Gombe ternary wastewater and was found suitable in removing all the lead and part of the zinc present. The result of the FTIR indicated that doum palm kernel is anionic in nature and hence adsorb positively charged ions present by chemisorption. The elemental composition of doum palm seed indicated its harmless properties. The chemical composition of Gombe ternary wastewater indicated $0.03 \mathrm{mg} / \mathrm{l}$ lead $(\mathrm{Pb})$, and $0.81 \mathrm{mg} / \mathrm{l}$ zinc $(\mathrm{Zn})$. 
Effect of dosage, time and temperature on lead and zinc biosorption were investigated. It was found out that at the available metal concentrations, lead has an optimum dosage of $167 \mathrm{mg} / \mathrm{l}$ whereas $835 \mathrm{mg} / \mathrm{l}$ was the optimum for zinc. When time was taken into consideration, the available lead in the wastewater sample was removed in less than 30 minutes while $90 \%$ of zinc was removed in 48 minutes at room temperature. When temperature was varied, $100 \%$ zinc removal was achieved at $50^{\circ} \mathrm{C}$.

\section{REFERENCES}

1. Agboinghale, F. (2014). Studies on the Use of Orange Peel for Adsorption of Congo Red Dye From Aqueous Solution. Computing, Information Systems, Development Informatics \& Allied Research Journal, 5(4), 37-44.

2. Ajmal, M., Hussain Khan, A., Ahmad, S., \& Ahmad, A. (1998). Role of sawdust in the removal of copper(II) from industrial wastes. Water Research, 32(10), 3085-3091. doi: 10.1016/s00431354(98)00067-0

3. Amin, M. T., Alazba, A. A., \& Shafiq, M. (2016). Adsorption of copper (Cu2+) from aqueous solution using date palm trunk fibre: isotherms and kinetics. Desalination and Water Treatment, 57(47), 22454-22466. doi: 10.1080/19443994.2015.1131635

4. Atieh, M. A. (2011). Removal of Zinc from Water Using Modified and Non-Modified Carbon Nanofibers. Retrieved from

https://www.researchgate.net/publication/266000622_Removal_of_Zinc_from_Water_Using_M odified_and_Non-Modified_Carbon_Nanofibers

5. Banerjee, K. (2012). A Novel Agricultural Waste Adsorbent, Watermelon Shell for the Removal of Copper from Aqueous Solutions. Iranica Journal of Energy \& Environment, 3(2), 143-156.

6. Besser, B. J. M., \& Leib, K. J. (2007). Toxicity of Metals in Water and Sediment to Aquatic Biota. Retrieved from https://www.researchgate.net/publication/249657972_Toxicity_of_Metals_in_Water_and_Sedi ment_to_Aquatic_Biota

7. Buljan, J. (2005). Costs of tannery waste treatment. Retrieved from https://leatherpanel.org/sites/default/files/publicationsattachments/costs_of_tannery_waste_treatment.pdf

8. Butu, A. W., \& Bichi, A. A. (2013). Assessment of some heavy elements in Galma dam, Zaria, Nigeria. International Journal of Development and Sustainability, 2(2), 686-696.

9. Chukwu, K. E. (2015). Water supply management policy in Nigeria: challenges in the wetland area of Niger delta. European Scientific Journal, 11(26), 303-323.

10. Coughlin, D., Looney, B., \& Millings, M. (2009). Chronic zinc screening water effect ratio for the $h-12$ outfall, Savannah River Site. doi: 10.2172/946164

11. Debora, J., Theodoro, P., Lenz, G. F., Zara, R. F., \& Bergamasco, R. (2013). Coagulants and Natural Polymers: Perspectives for the Treatment of Water. Plastic and Polymer Technology, 2(3), 55-62.

12. Government of Saskatchewan. (2010). Lead. Retrieved June 1, 2019, from http://www.saskh2o.ca/PDF-WaterCommittee/lead.pdf

13. Izah, S. C., \& Ineyougha, E. R. (2015). A review of the microbial quality of potable water sources in Nigeria. Journal of Advances in Biological and Basic Research, 1(1), 12-19.

14. Koo, W. K., Gani, N. a, Shamsuddin, M. S., Subki, N. S., \& Sulaiman, M. a. (2015). Comparison of Wastewater Treatment using Activated Carbon from Bamboo and Oil Palm: An Overview. Journal of Tropical Resources and Sustainable Science, 3(1), 54-60. 
15. Koppad, V. B. (2014). Development of Isotherms to Evaluate Removal of Dyes Using Adsorbents. The International Journal of Science \& Technoledge, 2(6), 116-124.

16. Küçükoğlu, M., Bİnokay, U. S., \& Pekmezekmek, A. B. (2013). The effects of zinc chloride during early embryonic development in zebrafish (Brachydanio rerio). Turkish Journal of Biology, 37, 158-164.

17. Kumar, S. S., Balaji, M., Anver, M. A., \& Majeetha, M. (2016). Application of Affluent Alfresco Plants as an Affordable Aid in the Treatment of Acquainted Effluents. International Journal for Innovative Research in Science \& Technology, 2(11), 205-210.

18. Makarski, B., \& Makarska, E. (2012). Effect of addition of $\mathrm{Ca}, \mathrm{Cu}, \mathrm{Fe}, \mathrm{Zn}$ and lactic acid to drinking water on content of these elements in muscles of slaughter turkeys. Journal of Elementology, (1/2010). doi: 10.5601/jelem.2010.15.1.119-129

19. Mandina, S., Chigondo, F., Shumba, M., Nyamunda, B. C., \& Sebata, E. (2013). Removal of chromium (VI) from aqueous solution using chemically modified orange (citrus cinensis ) peel. Journal of Applied Chemistry, 6(2), 66-75.

20. Othman, N., Mohd-Asharuddin, S., \& Azizul-Rahman, M. F. H. (2013). An Overview of Fruit Waste as Sustainable Adsorbent for Heavy Metal Removal. Applied Mechanics and Materials, 389, 29-35. doi: 10.4028/www.scientific.net/amm.389.29

21. Oushabi, A., Sair, S., Abboud, Y., Tanane, O., \& Bouari, A. E. L. (2015). Natural thermal-insulation materials composed of renewable resources: characterization of local date palm fibers (LDPF). Journal of Material and Environmental Science, 6(12), 3395-3402.

22. Palma, C., Carvajal, A., Vásquez, C., \& Contreras, E. (2011). Wastewater Treatment for Removal of Recalcitrant Compounds: A Hybrid Process for Decolorization and Biodegradation of Dyes. Chinese Journal of Chemical Engineering, 19(4), 621-625. doi: 10.1016/s1004-9541(11)60032-3

23. Tarachand, N., \& Dipak, S. (2016). Baobab fruit shell (Adansonia digitata) as a Natural Adsorbent for Copper and Lead Removal from Industrial Effluent. Research Journal of Chemical and Environmental Sciences, 4(29), 32-38.

24. Thomsen, V. (2007). Basic Fundamental Parameters in X-Ray Fluorescence. Spectroscopy, 22(5). Retrieved from http://www.spectroscopyonline.com/basic-fundamental-parameters-X-rayfluorescence

25. Yéwêgnon, N., Esther, A., Philippe, S., Abdoukarim, A., Abdou, Y., Alassane, K., ... Dominique, C. (2016). Evaluation of Aloe vera leaf gel as a Natural Flocculant: Phytochemical Screening and Turbidity removal Trials of water by Coagulation flocculation. Research Journal of Recent Sciences, 5(1), 9-15. 